\title{
Impact of cardiac arrest resuscitated donors on heart transplant recipients' outcome
}

Antonella Galeone, MD, PhD, ${ }^{\text {a }}$ Shaida Varnous, $\mathrm{MD},{ }^{\mathrm{a}}$ Guillaume Lebreton, MD, ${ }^{\mathrm{a}}$ Eleodoro Barreda, MD, ${ }^{\mathrm{a}}$ Sara Hariri, MD, ${ }^{\mathrm{b}}$ Alain Pavie, MD, ${ }^{\mathrm{a}}$ and Pascal Leprince, $\mathrm{MD}, \mathrm{PhD}^{\mathrm{a}}$

\section{ABSTRACT}

Objective: To evaluate the influence of cardiac arrest-resuscitated donors (CARDs) on the outcome of heart recipients.

Methods: Patients transplanted between July 2004 and December 2012 were divided into 2 groups according to the history of cardiac arrest in donors and their clinical records were retrospectively reviewed.

Results: A total of 584 heart transplantations were performed during the study period, and 117 recipients received an organ from a CARD. There were no differences between the 2 groups with regards to recipient age, sex, cardiomyopathy, preoperative extracorporeal membrane oxygenation, national high emergency waiting list, and redo surgery. Donors who sustained a cardiac arrest were significantly younger (44 [32-51] vs 49 [41-56] years; $P<.001$ ), their main cause of death was anoxia $(57 \%$ vs $1 \% ; P<.001)$, and they had significantly greater troponin T peak levels $(0.51$ [0.128-3.108] vs 0.11 [0.04-0.43] ng/mL; $P<.001)$. Median cardiac arrest duration was 15 minutes (5-25). No difference was noted in donors with regards to left ventricular ejection fraction at time of organ procurement $(62 \% \pm 8 \%$ vs $63 \% \pm 8 \% ; P=.2)$. There were no differences between the 2 groups with regards to ischemic time (179 \pm 60 vs $183 \pm 59$ minutes; $P=.43$ ), need for postoperative extracorporeal membrane oxygenation for primary graft failure $(31 \%$ vs $30 \% ; P=.993)$ and 30 -days mortality. Recipients receiving an organ from a CARD had a significantly better 10 year survival $(69.4 \%$ vs $50.4 \% ; P=.017)$.

Conclusions: History of cardiac arrest in donors with a preserved left ventricular ejection fraction at time of organ procurement doesn't affect outcome of heart recipients. (J Thorac Cardiovasc Surg 2017;153:622-30)

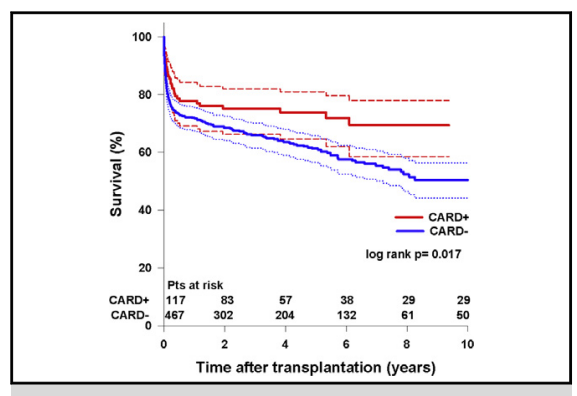

Recipient survival according to history of cardiac arrest in donors.

\section{Central Message}

History of cardiac arrest in donors with a preserved left ventricular ejection fraction at time of organ procurement doesn't affect outcome of heart recipients.

\section{Perspective}

The use of donors with history of cardiac arrest is safe and may increase donors' pool and reduce the gap between the growing number of recipients waiting for heart transplant and the ongoing organ shortage. The evidence that short period of ischemia due to cardiac arrest does not affect heart recipients outcome is an essential premise to perform heart transplant from non heart beating donors.

See Editorial Commentary page 631.
Heart transplantation represents the treatment of choice for patients with end-stage heart failure, providing improved quality of life and survival in these patients ${ }^{1}$; unfortunately not all patients can benefit from heart transplantation

\footnotetext{
From the Departments of ${ }^{\mathrm{a}}$ Thoracic and Cardiovascular Surgery and ${ }^{\mathrm{b}}$ Anesthesiology, University Pierre et Marie Curie, Paris 6, Assistance Publique des Hôpitaux de Paris, Groupe Hospitalier Pitié-Salpêtrière, Paris, France.

Received for publication Jan 3, 2016; revisions received Oct 16, 2016; accepted for publication Oct 20, 2016; available ahead of print Dec 6, 2016.

Address for reprints: Antonella Galeone, MD, PhD, Department of Thoracic and Cardiovascular Surgery, University Pierre et Marie Curie, Paris 6, Assistance Publique des Hôpitaux de Paris, Groupe Hospitalier Pitié-Salpêtrière, 47-83, boulevard de l'Hôpital, 75013 Paris, France (E-mail: a.galeone@email.it).

$0022-5223 / \$ 36.00$

Copyright (c) 2016 by The American Association for Thoracic Surgery

http://dx.doi.org/10.1016/j.jtcvs.2016.10.079
}

because of an organ donor shortage, which results in a mortality rate while on a waiting list that ranges from $12 \%$ up to $19 \%$ in greater-risk patients. ${ }^{2}$ One strategy to implement the limited organ availability is to expand criteria for acceptance of organ donors ${ }^{3}$; however, reluctance exists in accepting organs for transplantation from donors who sustained a cardiac arrest because of the concern that warm ischemic injury could negatively

Scanning this QR code will take you to a procedural video. 


\section{Abbreviations and Acronyms \\ CARD $=$ cardiac arrest - resuscitated donor \\ $\mathrm{CAV}=$ cardiac allograft vasculopathy \\ $\mathrm{ECMO}=$ extracorporeal membrane oxygenation \\ $\mathrm{EMB}=$ endomyocardial biopsy \\ HLA = human leukocyte antigen \\ LVAD $=$ left ventricular assist device \\ NHBD $=$ nonheart-beating donors \\ $\mathrm{PGF}=$ primary graft failure}

influence graft and patient survival. Recent studies showed that history of cardiac arrest resuscitation in donors is not associated with negative outcome in heart recipients ${ }^{4-6}$ or in other solid-organ recipients. ${ }^{7,8}$ In this study, we sought to evaluate the impact of cardiac arrest resuscitated donors on heart recipients' early and late outcome.

\section{PATIENTS AND METHODS Study Population}

The study protocol was approved by the institutional review board. Clinical records of all adult patients who underwent transplantation between July 2004 (when national high urgency inscription list was established in France) and December 2012 were reviewed retrospectively. Patients undergoing multiorgan and retransplantation were excluded from the study. Data were collected until June 2014. Patients were divided into 2 groups according to the history of cardiac arrest-resuscitated donors (CARDs), named respectively CARD + and CARD - group. Clinical records of donors were provided by the Agence de la Biomedicine, the French Agency for organ transplantation that guarantees for the accurateness of the information.

\section{Operative Technique}

Grafts were harvested from beating-heart brain-dead donors, preserved with the use of Celsior cardioplegic solution (IMTX Sangstat, Lyon, France), and stored in cold saline solution during transportation. Heart transplantation was performed according to the bicaval technique; to protect donor heart during implant, we used cold blood cardioplegia, and we performed all anastomoses with single aortic crossclamping (Video 1).

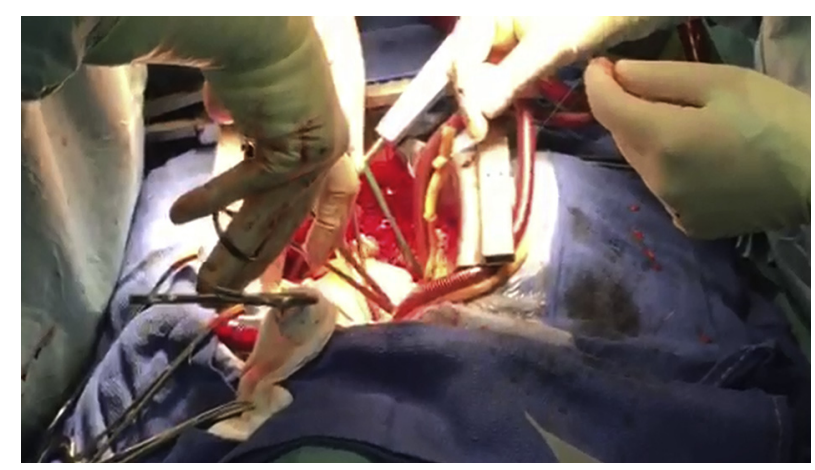

VIDEO 1. A crucial moment during the cardiac transplantation: after de-airing, the aortic crossclamp is removed and the cardiac activity restarts. Video available at: http://www.jtcvsonline.org/article/S0022-5223(16) 31487-8/addons.

\section{Immunosuppression}

All patients received immunosuppressive treatment consisting of antilymphocyte globulin (Thymoglobulin; Genzyme Transplant, Cambridge, Mass) at a dose of $1.5 \mathrm{mg} / \mathrm{kg} /$ day for the first 5 postoperative days and preoperative intravenous methylprednisolone and mycophenolate mofetil. Postoperatively, patients received cyclosporin 4 to $6 \mathrm{mg} / \mathrm{kg} / \mathrm{day}$ (target level $300 \mathrm{ng} / \mathrm{mL}$ ), mycophenolate mofetil $2 \mathrm{~g} / \mathrm{day}$, and prednisone $1 \mathrm{mg} / \mathrm{kg} / \mathrm{day}$, which was reduced progressively to $0.2 \mathrm{mg} / \mathrm{kg} / \mathrm{day}$. Minimization of immunosupression by lower levels of calcineurin inhibitor (adapted for serum level of 50-100 $\mathrm{ng} / \mathrm{mL}$ ) and corticosteroids (5-10 $\mathrm{mg} /$ day) was common practice and safe in this population.

Patients' regimens were modified during follow-up visits and switched to tacrolimus, sirolimus, or everolimus as appropriate (acute allograft rejection, cardiac allograft vasculopathy, malignancies). High-dose corticosteroid was the first-line therapy for acute cellular allograft rejection with grade more than 1R. Since 2008, the detection of pretransplant and posttransplant donor-specific anti-human leukocyte antigen (HLA) antibodies has been based on Luminex mixed class I and II Antibody Screening kits (One Lambda, Canoga Park, Calif); patients with a positive screen were characterized for HLA class I and/or class II antibody specificity with LABScreen Single Antigen beads (One Lambda, Canoga Park, Calif). Pretransplant as well as posttransplant plasmapheresis was performed in HLA-immunosensitized patients transplanted with donor-specific anti-HLA antibodies.

\section{Follow-up}

Patients were followed closely and received routine laboratory tests, clinical examination, echocardiography, endomyocardial biopsy (EMB), and coronary angiography according to our institutional protocols. Patients were monitored by repetitive EMBs to detect allograft rejection; EMBs were performed approximately 10 to 15 times during the first year posttransplant, 3 times during the second year, and twice a year from the third to the tenth year. Coronary angiography was performed every 2 years; in presence of cardiac allograft vasculopathy (CAV), coronary angiography was performed every year and in case of coronary angioplasty and stenting, a control angiography was performed 6 months after the procedure. The following posttransplant events were recorded for all patients: number and grade of acute cellular allograft rejection episode and the presence and grade of CAV defined according to The International Society for Heart \& Lung Transplantation classifications. ${ }^{9,10}$ Data were collected until the end of June 2014.

\section{Statistical Analysis}

Categorical variables are expressed as number and percentages and were compared with $\chi^{2}$ test. Continuous variables are expressed as the mean \pm 1 standard deviation and compared with the Student $t$ test, and continuous variables with a skewed distribution are presented as median and interquartile range and compared with Mann-Whitney $U$ test. The Kaplan-Meier method was used to draw survival curves and calculate 30-day, 1-, 5-, and 10-year survival, and the log-rank test was used to compare survival among groups. Hazard ratios for mortality were determined by univariable and multivariable Cox proportional hazards regression analysis with data presented as hazard ratio with $95 \%$ confidence intervals. A 2-tailed $P$ value of less than .05 was taken to indicate statistical significance. Statistical analysis was performed with SPSS 17.0 statistical software (SPSS Inc, Chicago, Ill).

\section{RESULTS}

From July 2004 to December 2012, a total of 625 heart transplantations were performed at our institution; 28 patients underwent multiorgan transplantation and 13 patients underwent retransplantation and were excluded from the study. One hundred seventeen recipients received 
TABLE 1. Donor characteristics

\begin{tabular}{|c|c|c|c|}
\hline & CARD $+\operatorname{group}(n=117)$ & CARD - group $(n=467)$ & $\boldsymbol{P}$ \\
\hline Age, y & $44(32-51)$ & $49(41-56)$ & $<.001$ \\
\hline Male sex & $70(60 \%)$ & $308(66 \%)$ & .258 \\
\hline Sex mismatch & $44(38 \%)$ & $149(32 \%)$ & .288 \\
\hline Donor F/recipient M & $33(75 \%)$ & $103(69 \%)$ & \\
\hline Donor M/recipient F & $11(25 \%)$ & $46(31 \%)$ & \\
\hline BMI & $26.2 \pm 5.2$ & $25.4 \pm 4.5$ & .08 \\
\hline Donor/recipient BMI ratio & $1.1 \pm 0.2$ & $1.1 \pm 0.2$ & .14 \\
\hline CMV mismatch (donor+/recipient-) & $27(23 \%)$ & $85(18 \%)$ & .286 \\
\hline Cause of death & & & $<.001$ \\
\hline Cerebrovascular accident & $23(20 \%)$ & $277(59 \%)$ & \\
\hline Trauma & $22(19 \%)$ & $147(31 \%)$ & \\
\hline Anoxia & $67(57 \%)$ & $3(1 \%)$ & \\
\hline Gunshot wound & $2(2 \%)$ & $23(5 \%)$ & \\
\hline Other & $3(3 \%)$ & $17(4 \%)$ & \\
\hline Suicide & $31(26 \%)$ & $27(6 \%)$ & $<.001$ \\
\hline Inotropic support & $103(88 \%)$ & $399(85 \%)$ & .566 \\
\hline Norepinephrine dose, $\mathrm{mg} / \mathrm{h}$ & $0.875(0.25-2)$ & $1(0.4-2)$ & .247 \\
\hline Total management time, $\mathrm{d}$ & $3.8(2.2-5.3)$ & $3.08(1.8-6.1)$ & .344 \\
\hline Cardiac arrest duration, min & $15(5-25)$ & - & \\
\hline $1-10$ & $49(42 \%)$ & & \\
\hline $11-20$ & $32(27 \%)$ & & \\
\hline $21-30$ & $20(17 \%)$ & & \\
\hline$>30$ & $16(14 \%)$ & & \\
\hline Troponin T peak level, ng/mL & $0.51(0.128-3.108)$ & $0.11(0.04-0.43)$ & $<.001$ \\
\hline LVEF, \% & $62 \pm 8$ & $63 \pm 8$ & .2 \\
\hline
\end{tabular}

$C A R D$, Cardiac arrest-resuscitated donor; $F$, female; $M$, male; $B M I$, body mass index; $C M V$, cytomegalovirus; $L V E F$, left ventricular ejection fraction.

an organ from a CARD and were assigned to CARD+ group, and the remaining 467 recipients were assigned to CARD- group. The use of donors who sustained a cardiac arrest increased with time: they represented $9 \%$ of all donors in 2004, 10\% in 2005, 26\% in $2006,21 \%$ in $2007,18 \%$ in 2008 and $2009,24 \%$ in $2010,29 \%$ in 2011 , and $19 \%$ in 2012 . In this series, up to $362(62 \%)$ donors were marginal donors: $117(20 \%)$ had history of cardiac arrest, $143(24 \%)$ had $>55$ years, $102(17 \%)$ had ischemic time $>4$ hours, $32(5 \%)$ had high dose inotropic support (noradrenaline $>4 \mathrm{mg} / \mathrm{h}$ ), 31 $(5 \%)$ had donor to recipient body mass index mismatch of greater than $20 \%, 26(4 \%)$ had left ventricular hypertrophy (septum $>13 \mathrm{~mm}), 25(5 \%)$ had cocaine abuse, $8(1 \%)$ had left ventricular ejection fraction $<45 \%$; and 96 $(16 \%)$ donors had 2 or more marginal donor criteria.

Characteristics of donors and recipients at the time of transplantation are illustrated in Tables 1 and 2, respectively. Of note, donors who sustained a cardiac arrest were significantly younger than donors who did not (44 [32-51] vs 49 [41-56] years; $P<.001)$ and had significantly greater serum troponin $\mathrm{T}$ peak levels $(0.51$ [0.128-3.108] vs 0.11 [0.04-0.43] ng/mL; $P<.001)$. Median cardiac arrest duration was 15 minutes (5-25); cardiac arrest duration was inferior to 10 minutes in 49 (42\%) donors, between 11 and 20 minutes in $32(27 \%)$ donors, between 21 and 30 minutes in $20(17 \%)$ donors, and more than
30 minutes in 16 (14\%) donors. No linear relationship was noted between troponine $\mathrm{T}$ serum levels and duration of cardiac arrest (Figure 1). The main cause of death of donors was anoxia in the CARD+ group and cerebrovascular accident in the CARD - group; no difference was observed between the 2 donors groups with respect to need for inotropic support ( $88 \%$ vs $85 \%, P=.566)$, norepinephrine dose $(0.875$ [0.25-2] vs 1 [0.4-2] $\mathrm{mg} / \mathrm{h} ; P=.247)$, left ventricular ejection fraction $(62 \% \pm 8 \%$ vs $63 \% \pm 8 \%$, $P=.2$ ), and total management time (accident to organ procurement duration) (3.8 [2.2-5.3] vs 3.0 [1.8-6.1] days; $P=.344)$. The 2 recipients groups were similar for age, sex, national high urgency inscription list, need for preoperative extracorporeal membrane oxygenation (ECMO), etiology of cardiomyopathy, and redo surgery; of note, recipients of the CARD + group had significantly more left ventricular assist device (LVAD) use compared with recipients of the CARD - group $(10 \%$ vs $4 \%$; $P=.007)$; however, there was no difference in the duration of LVAD support between the 2 groups (363 \pm 183 vs $392 \pm 189$ days; $P=.69$ ).

No difference was observed between the 2 groups with respect to ischemic time, need for postoperative ECMO for primary graft failure (PGF), or other early postoperative complications (Table 2). Donors of recipients who needed a postoperative ECMO $(\mathrm{n}=177,30 \%)$ had similar troponin $\mathrm{T}$ peak levels 
TABLE 2. Recipients' preoperative and early postoperative characteristics

\begin{tabular}{|c|c|c|c|}
\hline & $\begin{array}{c}\text { CARD+ } \\
\text { group } \\
(\mathrm{n}=\mathbf{1 1 7}) \\
\end{array}$ & $\begin{array}{c}\text { CARD- } \\
\text { group } \\
(n=467) \\
\end{array}$ & $\boldsymbol{P}$ \\
\hline \multicolumn{4}{|l|}{ Preoperative characteristics } \\
\hline Age, y & $49 \pm 13$ & $49 \pm 14$ & .91 \\
\hline Male sex & $92(79 \%)$ & $363(78 \%)$ & .932 \\
\hline \multicolumn{4}{|l|}{ National high emergency waiting list } \\
\hline High Urgency 1 & $35(30 \%)$ & $172(37 \%)$ & .197 \\
\hline High Urgency 2 & $6(5 \%)$ & $26(6 \%)$ & .968 \\
\hline Preoperative ECMO & $14(12 \%)$ & $73(16 \%)$ & .395 \\
\hline Time on ECMO, d & $10 \pm 9$ & $14 \pm 19$ & .41 \\
\hline LVAD & $12(10 \%)$ & $17(4 \%)$ & .007 \\
\hline Time on LVAD, $\mathrm{d}$ & $363 \pm 183$ & $392 \pm 189$ & .69 \\
\hline BIVAD or TAH & $5(4 \%)$ & $24(5 \%)$ & .883 \\
\hline Time on BIVAD or TAH, $\mathrm{d}$ & $75 \pm 46$ & $173 \pm 140$ & .13 \\
\hline Redo surgery & $42(37 \%)$ & $157(33 \%)$ & .722 \\
\hline Dilated cardiomyopathy & $48(41 \%)$ & $199(43 \%)$ & .837 \\
\hline Ischemic cardiomyopathy & $47(40 \%)$ & $151(32 \%)$ & .136 \\
\hline Valvular cardiomyopathy & $7(6 \%)$ & $27(6 \%)$ & .891 \\
\hline Hypertrophic cardiomyopathy & $3(3 \%)$ & $17(4 \%)$ & .773 \\
\hline \multicolumn{4}{|l|}{ Early postoperative characteristics } \\
\hline Ischemic time, $\min$ & $179 \pm 60$ & $183 \pm 59$ & .43 \\
\hline $\mathrm{CPB}$ time, $\min$ & $115 \pm 53$ & $115 \pm 49$ & .97 \\
\hline Postoperative ECMO, total & $36(31 \%)$ & $141(30 \%)$ & .993 \\
\hline Pre- and postoperative ECMO & $7(6 \%)$ & $32(7 \%)$ & \\
\hline Postoperative ECMO only & $29(25 \%)$ & $109(23 \%)$ & \\
\hline Plasmapheresis & $16(14 \%)$ & $86(18 \%)$ & .284 \\
\hline Mechanical ventilation $>48 \mathrm{~h}$ & $52(44 \%)$ & $258(55 \%)$ & .05 \\
\hline Hyperacute rejection & 1 & 2 & .884 \\
\hline Hemodialysis & $29(25 \%)$ & $138(29 \%)$ & .365 \\
\hline Multiple organ failure & $17(15 \%)$ & $101(21 \%)$ & .114 \\
\hline Sepsis & $22(19 \%)$ & $96(20 \%)$ & .769 \\
\hline Cerebrovascular accident & $9(8 \%)$ & $27(6 \%)$ & .58 \\
\hline Re-exploration for bleeding & $8(7 \%)$ & $50(11 \%)$ & .281 \\
\hline
\end{tabular}

compared with donors of recipients who did not $(\mathrm{n}=407,70 \%) \quad(0.15 \quad[0.05-1.1] \quad \mathrm{ng} / \mathrm{mL}$ vs 0.15 [0.04-0.61] ng/mL; $P=.227)$. Recipients requiring a postoperative ECMO for primary graft dysfunction $(\mathrm{n}=177,30 \%)$ were more critical compared with recipients who did not; they were frequently older than 60 years $(25 \%$ vs $17 \%, P=.03)$, had more preoperative ECMO $(34 \%$ vs $12 \% ; P<.001)$, were more frequently redux $(45 \%$ vs $29 \% ; P<.001)$, and required plasmapheresis more frequently for alloimmunization $(24 \%$ vs $15 \% ; P=.012)$. Donors with previous cardiac arrest turned down for heart transplantation also were evaluated; 603 donors were not used for transplantation during the study period, and $137(23 \%)$ of them had a history of cardiac arrest. Donors with previous cardiac arrest not used had similar age (45 [31-54] years

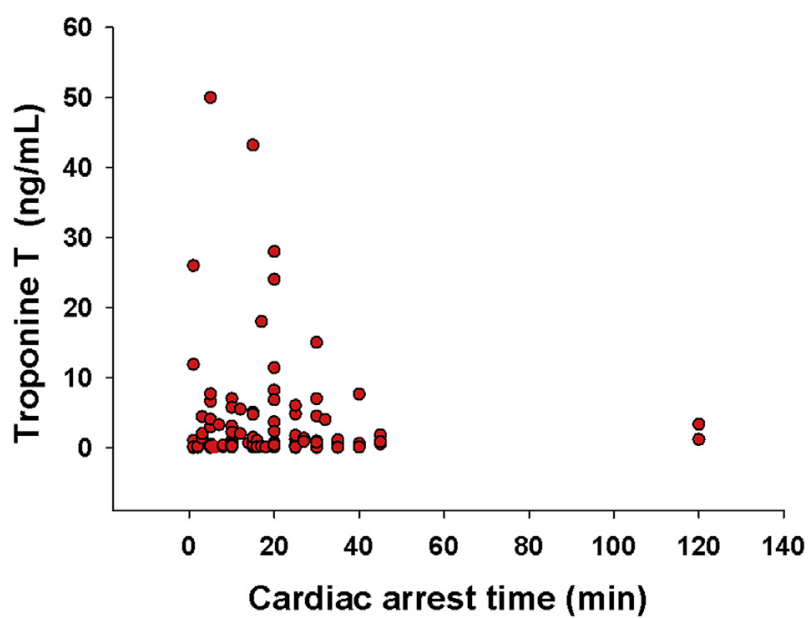

FIGURE 1. Plot showing relationship between serum troponin $T$ peak levels $(\mathrm{ng} / \mathrm{mL})$ and cardiac arrest duration (minutes).

vs 44 [32-51] years; $P=0542)$, cardiac arrest time (15 [7-25] minutes vs 15 [5-25] minutes; $P=.995)$ and serum troponine $\mathrm{T}$ peak levels $(0.35[0.1-2.77] \mathrm{ng} / \mathrm{mL}$ vs $0.51[0.128-3.108] \mathrm{ng} / \mathrm{mL} ; P=.335$ ) with respect to donors with previous cardiac arrest used for heart transplantation; however, they had significantly greater norepinephrine doses (1.5 [0.5-3.84] $\mathrm{mg} / \mathrm{h}$ vs $0.875[0.25-2] \mathrm{mg} / \mathrm{h} ; P<.001)$ and lower left ventricular ejection fraction $(58 \% \pm 10 \%$ vs $62 \% \pm 8 \%$; $P=.005)$.

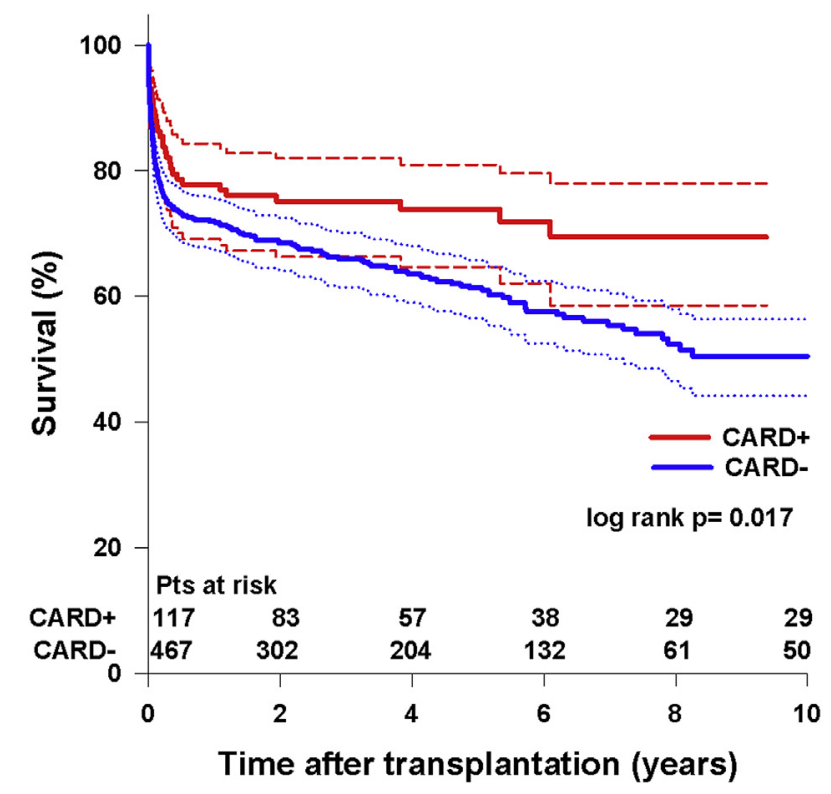

FIGURE 2. Kaplan-Meier curves for long-term survival in recipient according to history of cardiac arrest in donors. CARD, Cardiac arrestresuscitated donor. 
TABLE 3. Recipients' main causes of death

\begin{tabular}{|c|c|c|c|c|}
\hline & \multicolumn{2}{|c|}{ 30-d mortality } & \multicolumn{2}{|c|}{ Late mortality } \\
\hline & $\begin{array}{c}\text { CARD }+ \text { group } \\
(\mathrm{n}=\mathbf{1 2} / \mathbf{1 1 7}, \mathbf{1 0} \%)\end{array}$ & $\begin{array}{c}\text { CARD - group } \\
(n=79 / 467,17 \%)\end{array}$ & $\begin{array}{c}\text { CARD }+ \text { group } \\
(\mathbf{n}=\mathbf{2 0} / \mathbf{1 0 5}, \mathbf{1 9} \%)\end{array}$ & $\begin{array}{c}\text { CARD- group } \\
(\mathrm{n}=\mathbf{1 1 2} / \mathbf{3 8 8}, \mathbf{2 9} \%)\end{array}$ \\
\hline Graft dysfunction & $2(17)$ & $31(39)$ & $1(5)$ & 0 \\
\hline Sepsis & $5(42)$ & $18(23)$ & $12(60)$ & $44(39)$ \\
\hline CVA & $2(17)$ & $8(10)$ & $2(10)$ & $7(6)$ \\
\hline MOF & $1(8)$ & $7(9)$ & 0 & 0 \\
\hline Hemorrhagic shock & $2(17)$ & $4(5)$ & 0 & $5(4)$ \\
\hline Cardiac arrest & 0 & $7(9)$ & $1(5)$ & $20(18)$ \\
\hline Acute rejection & 0 & $2(3)$ & $3(15)$ & $5(4)$ \\
\hline CAV & 0 & 0 & $1(5)$ & $12(11)$ \\
\hline Cancer & 0 & 0 & 0 & $10(9)$ \\
\hline Pulmonary embolism & 0 & 0 & 0 & $2(2)$ \\
\hline Other & 0 & $2(2)$ & 0 & $7(6)$ \\
\hline
\end{tabular}

$C A R D$, Cardiac arrest-resuscitated donor; $C V A$, cerebrovascular accident; $M O F$, multiple organ failure; $C A V$, cardiac allograft vasculopathy.

\section{Recipient Survival}

At the end of the follow-up, a total of 223 events were recorded, including 221 deaths and 2 retransplantations; in particular, we recorded 32 events in the CARD+ group, including 31 deaths and 1 retransplantation for primary graft dysfunction and 191 events in the CARDgroup, including 190 deaths and 1 retransplantation for chronic allograft rejection. The median follow up was 4.7 years [7.4-3.2] in the CARD+ group and 5.6 [7.8-3.4] years in the CARD - group $(P=.016)$. Kaplan-Meier analysis showed a mean survival time of $6.8 \pm 0.3$ and $6.1 \pm 0.2$ years in the CARD + group and in the CARD - group, respectively. There was no difference in 30 -day and 1-year mortality between the 2 groups; the survival rates were $89.7 \%$ at 30 days and $77.8 \%$ at 1 year in the CARD+ group and $83.3 \%$ at 30 days and $71.9 \%$ at 1 year in the CARD- group. At 5 years and at 10 years, however, CARD - patients showed a significantly lower survival rate compared with CARD + patients: $61.3 \%$ versus $73.8 \%(P=.032)$, respectively, at 5 years and $50.4 \%$ versus $69.4 \%$ respectively $(P=.017)$ at 10 years (Figure 2). The main causes of 30-day and late mortality are listened in Table 3. No difference was observed in donors' troponine $\mathrm{T}$ peak levels of recipients who died at 30 day after heart transplant $(\mathrm{n}=91 / 584,16 \%)$ compared with recipients who did not $(\mathrm{n}=493 / 584,84 \%)(0.15$; [0.05-0.65] ng/mL vs 0.15 [0.04-0.72] ng/mL; $P=.896$ ); likewise, there was no difference in donors troponine $\mathrm{T}$ peak levels between recipients who died within the first year after transplant $(157,23 \%)$ compared with recipients who survived past 1 year $(427,73 \%)(0.12$ [0.04-0.515] $\mathrm{ng} / \mathrm{mL}$ vs 0.15 [0.05-0.74] $\mathrm{ng} / \mathrm{mL} ; P=.159)$. We additionally evaluated the recipient survival in patients belonging to the CARD + group, according to the donor's
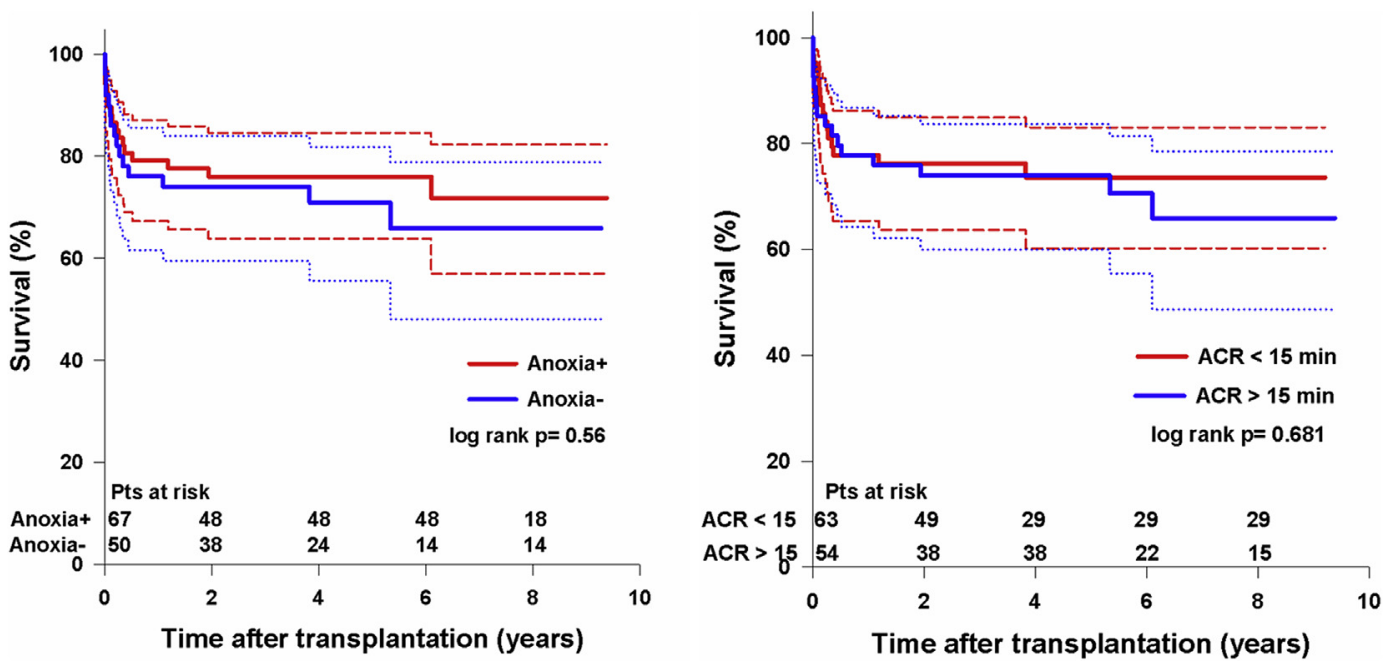

FIGURE 3. Kaplan-Meier curves for long-term survival in CARD + group recipients according to donor cause of death (left) and duration of cardiac arrest (right). 
TABLE 4. Risk factors of 1-year mortality at univariable and multivariable analysis

\begin{tabular}{|c|c|c|c|c|}
\hline & \multicolumn{2}{|c|}{ Univariable analysis } & \multicolumn{2}{|c|}{ Multivariable analysis } \\
\hline & Hazard ratio $(95 \%$ CI) & $\boldsymbol{P}$ & Hazard ratio $(95 \%$ CI $)$ & $\boldsymbol{P}$ \\
\hline Donor age > 55 y (Q4) & $1.401(0.995-1.971)$ & .052 & & \\
\hline Cardiac arrest in donor & $0.751(0.493-1.143)$ & .181 & & \\
\hline Troponin $>0.7 \mathrm{ng} / \mathrm{mL}(\mathrm{Q} 4)$ & $0.885(0.608-1.288)$ & .523 & & \\
\hline Recipient age & $1.014(1.002-1.027)$ & .028 & $1.013(1.002-1.025)$ & .027 \\
\hline National High Urgency 1 & $0.854(0.612-1.193)$ & .355 & & \\
\hline Preoperative ECMO & $1.186(0.784-1.796)$ & .419 & & \\
\hline Preoperative LVAD & $0.753(0.325-1.662)$ & .460 & & \\
\hline Postoperative ECMO & $5.325(3.853-7.357)$ & $<.001$ & $5.331(3.858-7.367)$ & $<.001$ \\
\hline Plasmapheresis & $0.789(0.507-1.228)$ & .294 & & \\
\hline
\end{tabular}

CI, Confidence interval; ECMO, extracorporeal membrane oxygenation; $L V A D$, left ventricular assist device.

cause of death and the duration of cardiac arrest. We found no difference in early and late survival rate between patients whose donors brain death was due to anoxia $(n=67,57 \%)$ and patients whose donors brain death was not due to anoxia $(\mathrm{n}=50,43 \%)(89.6 \%$ vs $90.0 \%$ at 30 days, $P=.95$; $71.8 \%$ vs $65.9 \%$ at 10 years, $P=.56$ ) (Figure 3 , left). Likewise, there was no difference in survival rate at 10 years between recipients whose donors sustained a cardiac arrest $\leq 15$ minutes $(\mathrm{n}=63,54 \%)$ and recipients whose donors sustained a cardiac arrest $>15$ minutes $(\mathrm{n}=54,46 \%)$ (73.6\% vs $65.9 \% ; P=.68$ ) (Figure 2 , right). In addition, there was no difference in 10-year survival between donors who sustained a cardiac arrest $\leq 10$ minutes $(n=49)$ and donors who sustained a cardiac arrest $>30$ minutes $(\mathrm{n}=16)(72.8 \%$ vs $81.3 \% ; P=.527)$.

Univariable analysis was performed with the following variables: donors age $>55$ years $(\mathrm{Q} 4)$, history of cardiac arrest in donor, troponin $\mathrm{T}$ peak serum level $>0.7 \mathrm{ng} / \mathrm{mL}$ (Q4), recipient age, preoperative ECMO, preoperative LVAD, national high urgency, postoperative ECMO, and plasmapheresis (Tables 4 and 5); significant variables at univariable analysis were entered in the Cox multivariable regression. Multivariable analysis showed that recipient age and postoperative ECMO were independent risk factors of 1-year mortality (Table 4 ), whereas donor age $>55$ years
(Q4), cardiac arrest, recipient age, and postoperative ECMO were independent risk factors of long-term mortality (Table 5).

\section{Allograft Rejection}

One hundred seven $(91 \%)$ recipients of the CARD + group and 398 (85\%) of the CARD - group had a least one endomyocardial biopsy during the follow-up. Acute cellular allograft rejection was histologically recorded in $63(54 \%)$ recipients of the CARD + group and in $241(52 \%)$ recipients of the CARD- group. Survival free from acute allograft rejection was $31.3 \%$ in the CARD + group and $30.4 \%$ in the CARD- group $(P=.439)$ (Figure 4).

\section{Cardiac Allograft Vasculopathy}

Three hundred eleven (67\%) recipients in the CARDgroup and $87(74 \%)$ in the CARD+ group received a least one coronary angiography during the follow-up. CAV grade 2 was diagnosed in $7(6 \%)$ patients of the CARD + group and in $25(5 \%)$ patients of the CARD - group and CAV grade 3 was diagnosed in $2(2 \%)$ patients of the CARD + group and in $15(4 \%)$ patients of the CARDgroup. Nine patients $(8 \%)$ of the CARD + group and 36 $(8 \%)$ patients of the CARD- group underwent one or

TABLE 5. Risk factors of 10-year mortality at univariable and at multivariable analysis

\begin{tabular}{|c|c|c|c|c|}
\hline & \multicolumn{2}{|c|}{ Univariable analysis } & \multicolumn{2}{|c|}{ Multivariable analysis } \\
\hline & Hazard ratio $(95 \%$ CI $)$ & $\boldsymbol{P}$ & Hazard ratio $(95 \% \mathrm{CI})$ & $\boldsymbol{P}$ \\
\hline Donor age $>55$ y $(\mathrm{Q} 4)$ & $1.432(1.075-1.906)$ & .014 & $1.556(1.165-2.079)$ & .003 \\
\hline Cardiac arrest in donor & $0.63(0.437-0.924)$ & .018 & $0.646(0.444-0.941)$ & .023 \\
\hline Troponin $>0.7 \mathrm{ng} / \mathrm{mL}(\mathrm{Q} 4)$ & $0.843(0.6-1.164)$ & .3 & & \\
\hline Recipient age & $1.016(1.005-1.027)$ & .003 & $1.015(1.005-1.025)$ & .003 \\
\hline National High Urgency 1 & $0.848(0.639-1.124)$ & .252 & & \\
\hline Preoperative ECMO & $1.213(0.852-1.727)$ & .284 & & \\
\hline Preoperative LVAD & $0.779(0.384-1.580)$ & .489 & & \\
\hline Postoperative ECMO & $3.823(2.930-4.988)$ & $<.001$ & $4.021(3.075-5.257)$ & $<.001$ \\
\hline Plasmapheresis & $0.908(0.623-1.325)$ & .618 & & \\
\hline
\end{tabular}

CI, Confidence interval; ECMO, extracorporeal membrane oxygenation; $L V A D$, left ventricular assist device. 

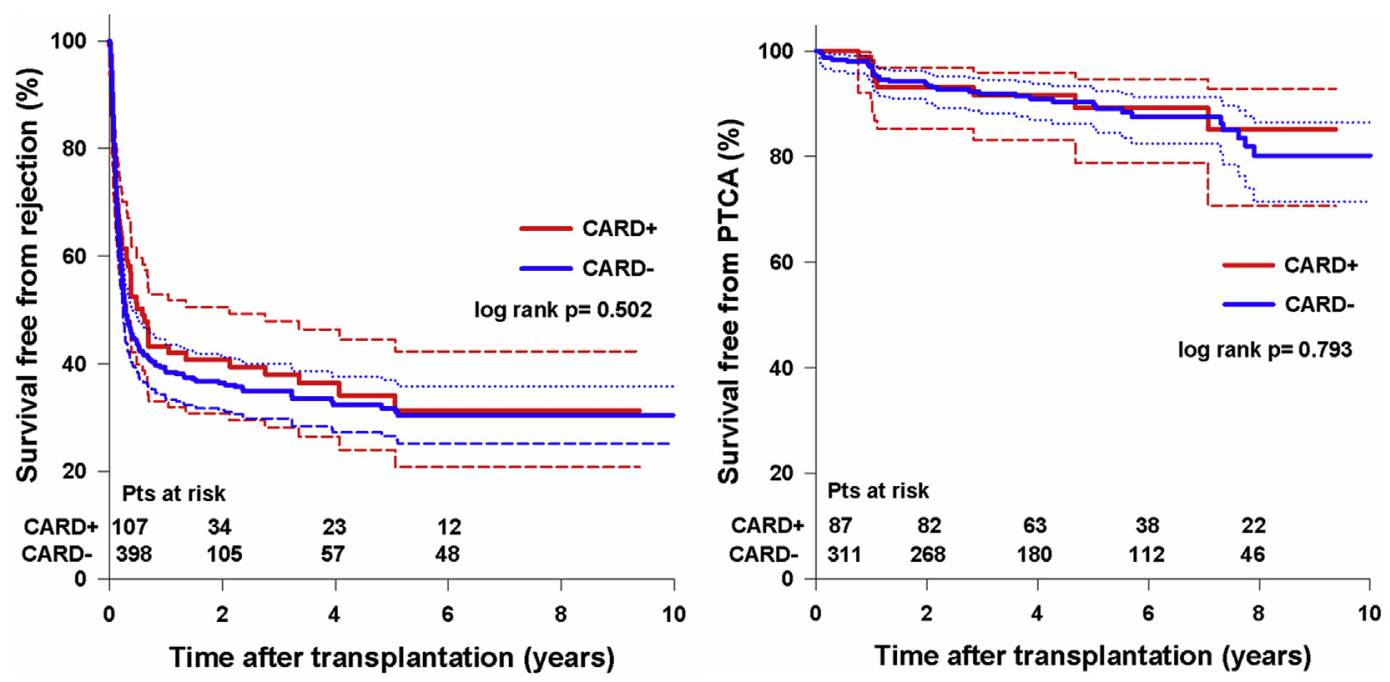

FIGURE 4. Kaplan-Meier curves for long-term survival free from acute allograft rejection (left) and cardiac allograft vasculopathy (right). CARD, Cardiac arrest-resuscitated donor; $P T C A$, percutaneous transluminal coronary angioplasty.

more percutaneous transluminal coronary angioplasty with stenting; no patient underwent coronary artery bypass grafting. Survival free from percutaneous transluminal coronary angioplasty was $85.2 \%$ in the CARD + group and $80.2 \%$ in the CARD - group $(P=.793)$ (Figure 4).

\section{DISCUSSION}

We report a single center's heart transplantation results, focusing on the impact of cardiac arrest resuscitation in donors on recipients' survival and outcome. The first important finding of this report is that there is no difference in 30-day and 1-year survival between recipients who received an organ from a CARD and recipients who did not. We also found no difference between the 2 groups with respect to the recipient' postoperative need for ECMO for PGF or other early postoperative complications. These results are consistent with previous studies that did not show inferior outcome in recipients of heart transplantation from selected CARDs. ${ }^{4,5}$ The reported incidence of PGF after heart transplantation varies widely between studies, with estimates ranging between 2.3 and $26 \%{ }^{11}$; most of the variability can be attributed to the different definitions of PGF used by different authors. When PGF has been defined as the need for high-dose inotropes or mechanical assist devices in the immediate posttransplant period, most investigators have reported incidence rates of $10 \%$ to $20 \%$ or greater. ${ }^{12}$ In our series, the incidence of PGF is about $30 \%$ in both groups and could be explained by the changing demographics of donors and recipients observed over the last years and the increased use of marginal donors.

The second and unexpected finding of this report is a significantly better long-term survival in recipients receiving an organ from a CARD. Possible explanations for these results are the younger age of donors who sustained a cardiac arrest in our series as well as the ischemic preconditioning effect of cardiac arrest. Donor age at transplantation is a well recognized factor having a positive effect on heart recipient survival ${ }^{13,14}$; each 1 -year reduction in donor age is associated with a $1 \%$ improvement in the likelihood of 10-year survival, which means that each decade decrease in donor age produces a $10 \%$ increase in the odds of 10 -year survival. ${ }^{15} \mathrm{In}$ addition, younger marginal donors with left ventricular dysfunction can completely recover to normal function over time before or after to heart transplantation. ${ }^{16,17}$ Organ ischemia due to the cardiac arrest could act as an ischemic preconditioning, thus protecting the myocardium from the subsequent ischemia/reperfusion injury occurring during transplantation. Ischemic preconditioning refers to the ability of short periods of ischemia to make the myocardium more resistant to a further and longer ischemic insult. This term was firstly introduced by Murry and colleagues,${ }^{18}$ who found that brief periods of ischemia accompanied by reperfusion just before sustained ischemia have multiple effects as: delay in ATP depletion, reduction in oxygen consumption, conservation of intracellular structure, and a delay or reduction of cellular necrosis due to ATP expiration, finally resulting in reduction of infarct size, despite an increase in the total ischemic period.

The strength of protection by ischemic preconditioning critically depends on the duration from the end of preconditioning ischemia to the onset of the subsequent ischemia; in fact, the protective effects of preconditioning are transient and last for less than 2 hours $^{19}$; however, a 
so-called second window of protection or delayed ischemic preconditioning has been shown to occur 24 hours after the preconditioning stimulus and lasting for about 48 hours. $^{20}$

Of note, we found no difference in recipient survival with respect to the duration of cardiac arrest in donors; these results are in contrast with previous report showing that increasing duration of cardiac arrest in donors was associated with decreased survival in recipients. $^{21}$ Despite the presence of more patients with preoperative LVAD in the CARD + group, early and late survival in this group was not inferior to the CARD - group. This finding is consistent with recent reports showing an ongoing posttransplant survival improvement in patients implanted with LVAD as a bridge to transplant. ${ }^{22}$

Finally, we found no difference in the occurrence of CAV and allograft rejection, that are well known complications affecting recipients' long-term survival after heart transplantation. ${ }^{23}$ All these findings are of an extreme importance because actually donors with a history of cardiac arrest are considered as marginal donors and usually refused as heart donors. Our results show that donors who sustained a cardiac arrest and recuperated a normal left ventricular function at time of organ procurement can be proposed and accepted for heart transplantation to any kind of recipient. In fact in our series there was no difference between the 2 recipients groups with respect to high national urgency inscription list, meaning that marginal donors were not proposed more often to sicker or more unstable patients. The use of donors with a history of cardiac arrest is safe and may increase donors' pool, thus reducing the gap between the growing number of recipients waiting for transplantation and the ongoing shortage of organs. ${ }^{24}$ Once stated that a short period of ischemia due to cardiac arrest does not negatively affect early and late recipients' outcome, the next step to improve organ donor pool could be to perform heart transplantation from nonheart-beating donors (NHBDs). Although only a case report of heterotopic heart transplantation ${ }^{25}$ and small series of 3 pediatric $^{26}$ and 3 adult $^{27}$ heart transplantation from NHBD have been published, promising results have been obtained in other solid-organ transplant. ${ }^{28-31}$ The heart from NHBD sustains an obligatory hypoxic cardiac arrest and a warm ischemic period before organ procurement; subsequent reperfusion leads to intracellular $\mathrm{Ca}^{2+}$ overload, reactive oxygen species, and an inflammatory response that result in myocardial injury. ${ }^{32}$ Ex vivo heart perfusion has been proposed initially as a means to resuscitate hearts from cardiocirculatory death donors and expand the donor pool $^{33}$; further experimental studies have been performed and different perfusion techniques have been investigated to minimize organ injury and improve organ recovery. ${ }^{34,35}$

\section{Limitations of the Study}

Clinical records of donors were provided by the French Agency for organ transplantation that guarantees for the accurateness of the information. For some donors, cardiac arrest was not witnessed, so that cardiac arrest duration refers to low-flow and the no-flow time is sometimes unknown. Data and results come from a single center and may not be applicable to other centers or countries.

\section{CONCLUSIONS}

New strategies are required to increase the number of organs available for transplantation, including expansion of donor criteria, use of NHBDs, and development of optimal preservation and perfusion techniques for the reconditioning of the heart after cardiac arrest. Myocardial ischemic injury after cardiac arrest in heart donors is of great concern, because it can result in poor graft and recipient survival. Our series shows that history of cardiac arrest resuscitation in donors with a preserved left ventricular function at time of organ procurement doesn't affect early and late outcome of heart recipients.

\section{Conflict of Interest Statement}

Authors have nothing to disclose with regard to commercial support.

\section{References}

1. Kittleson MM, Kobashigawa JA. Management of advanced heart failure: the role of heart transplantation. Circulation. 2011;123:1569-74.

2. Singh TP, Milliren CE, Almond CS, Graham D. Survival benefit from transplantation in patients listed for heart transplantation in the United States. J Am Coll Cardiol. 2014;63:1169-78.

3. Carrier M, Lizé JF. Impact of expanded-criteria donors on patient survival after heart, lung, liver and combined organ transplantation. Transplant Proc. 2012;44: 2231-4.

4. Ali AA, Lim E, Thanikachalam M, Sudarshan C, White P, Parameshwar J, et al Cardiac arrest in the organ donor does not negatively influence recipient survival after heart transplantation. Eur J Cardiothorac Surg. 2007;31:929-33.

5. Quader MA, Wolfe LG, Kasirajan V. Heart transplantation outcomes from cardiac arrest-resuscitated donors. J Heart Lung Transplant. 2013;32:1090-5.

6. L'Ecuyer T, Sloan K, Tang L. Impact of donor cardiopulmonary resuscitation on pediatric heart transplant outcome. Pediatr Transplant. 2011;15:742-5.

7. Wilson DJ, Fisher A, Das K, Goerlitz F, Holland BK, De La Torre AN, et al. Donors with cardiac arrest: improved organ recovery but no preconditioning benefit in liver allografts. Transplantation. 2003;75:1683-7.

8. Pilarczyk K, Osswald BR, Pizanis N, Tsagakis K, Massoudy P, Heckmann J, et al. Use of donors who have suffered cardiopulmonary arrest and resuscitation in lung transplantation. Eur J Cardiothorac Surg. 2011;39:342-7.

9. Stewart S, Winters GL, Fishbein MC, Tazelaar HD, Kobashigawa J, Abrams J, et al. Revision of the 1990 working formulation for the standardization of nomenclature in the diagnosis of heart rejection. J Heart Lung Transplant. 2005;24:1710-20.

10. Mehra MR, Crespo-Leiro MG, Dipchand A, Ensminger SM, Hiemann NE, Kobashigawa JA, et al. International Society for Heart and Lung Transplantation working formulation of a standardized nomenclature for cardiac allograft vasculopathy-2010. J Heart Lung Transplant. 2010;29:717-27.

11. Iyer A, Kumarasinghe G, Hicks M, Watson A, Gao L, Doyle A, et al. Primary graft failure after heart transplantation. J Transplant. 2011;2011:175768.

12. D'Alessandro C, Golmard JL, Barreda E, Laali M, Makris R, Luyt CE, et al Predictive risk factors for primary graft failure requiring temporary extra-corporeal membrane oxygenation support after cardiac transplantation in adults. Eur J Cardiothoracic Surg. 2011;40:962-9. 
13. John R, Rajasinghe HA, Itescu S, Suratwala S, Lietz K, Weinberg AD, et al. Factors affecting long-term survival (>10 years) after cardiac transplantation in the cyclosporine era. J Am Coll Cardiol. 2001;37:189-94.

14. Del Rizzo DF, Menkis AH, Pflugfelder PW, Novick RJ, McKenzie FN, Boyd WD, et al. The role of donor age and ischemic time on survival following orthotopic heart transplantation. J Heart Lung Transpl. 1999;18:310-9.

15. Kilic A, Weiss ES, George TJ, Arnaoutakis GJ, Yuh DD, Shah AS, et al. What predicts long-term survival after heart transplantation? An analysis of 9,400 ten-year survivors. Ann Thorac Surg. 2012;93:699-704.

16. Kono $\mathrm{T}$, Nishina $\mathrm{T}$, Morita $\mathrm{H}$, Hirota $\mathrm{Y}$, Kawamura $\mathrm{K}$, Fujiwara A. Usefulness of low dose dobutamine stress echocardiography for evaluating reversibility of brain death-induced myocardial dysfunction. Am J Cardiol. 1999;84:578-82.

17. Jeevanandam V, Furukawa S, Prendergast TW, Todd BA, Eisen HJ, McClurken JB. Standard criteria for an acceptable donor heart are restricting heart transplantation. Ann Thorac Surg. 1996;62:1268-75.

18. Murry CE, Jennings RB, Reimer KA. Preconditioning with ischemia: a delay of lethal cell injury in ischemic myocardium. Circulation. 1986;74:1124-36.

19. Downey JM, Cohen MV. Mechanisms of preconditioning: correlates and epiphenomena. In: Marber MS, Yellon DM, eds. Ischemia: Preconditioning and Adaptation. Oxford, UK: BIOS Scientific Publishers Limited; 1996:21-34.

20. Yellon DM, Baxter GF. A "second window of protection" or delayed preconditioning phenomenon: future horizons for myocardial protection? J Mol Cell Cardiol. 1995;27:1023-34.

21. Southerland KW, Castleberry AW, Williams JB, Daneshmand MA, Ali AA, Milano CA. Impact of donor cardiac arrest on heart transplantation. Surgery. 2013; 154:312-9.

22. Kamdar F, John R, Eckman P, Colvin-Adams M, Shumway SJ, Liao K. Postcardiac transplant survival in the current era in patients receiving continuous-flow left ventricular assist devices. J Thorac Cardiovasc Surg. 2013;145:575-81.

23. Galeone A, Kirsch M, Barreda E, Fernandez F, Vaissier E, Pavie A, et al. Clinical outcome and quality of life of patients surviving 20 years or longer after heart transplantation. Transpl Int. 2014;27:576-82.

24. Sandroni C, Adrie C, Cavallaro F, Marano C, Monchi M, Sanna T, et al. Are patients brain-dead after successful resuscitation from cardiac arrest suitable as organ donors? A systematic review. Resuscitation. 2010;81:1609-14.
25. Chiu KM, Lin TY, Chu SH. Successful heterotopic heart transplant after cardiopulmonary bypass rescue of an arrested donor heart. Transplant Proc. 2006;38:1514.

26. Boucek MM, Mashburn C, Dunn SM, Frizell R, Edwards L, Pietra B, et al. Pediatric heart transplantation after declaration of cardiocirculatory death. N Engl J Med. 2008;359:709-14.

27. Dhital KK, Iyer A, Connellan M, Chew HC, Gao L, Doyle A, et al. Adult heart transplantation with distant procurement and ex-vivo preservation of donor hearts after circulatory death: a case series. Lancet. 2015;385:2585-91.

28. Dominguez-Gil B, Haase-Kromwijk B, Van Leiden H, Neuberger J, Coene L, Morel P, et al. Current situation of donation after circulatory death in European countries. Transpl Int. 2011;24:676-86.

29. Krutsinger D, Reed RM, Blevins A, Puri V, De Oliveira NC, Zych B, et al. Lung transplantation from donation after cardiocirculatory death: a systematic review and meta-analysis. J Heart Lung Transplant. 2015;34:675-84.

30. Monbaliu D, Pirenne J, Talbot D. Liver transplantation using donation after cardiac death donors. J Hepatol. 2012;56:474-85.

31. Summers DM, Watson CJ, Pettigrew GJ, Johnson RJ, Collett D, Neuberger JM, et al. Kidney donation after circulatory death (DCD): state of the art. Kidney Int. 2015;88:241-9.

32. Perrelli MG, Pagliaro P, Penna C. Ischemia/reperfusion injury and cardioprotective mechanisms: role of mitochondria and reactive oxygen species. World J Cardiol. 2011;3:186-200.

33. Collins MJ, Moainie SL, Griffith BP, Poston RS. Preserving and evaluating hearts with ex vivo machine perfusion: an avenue to improve early graft performance and expand the donor pool. Eur J Cardiothorac Surg. 2008;34:318-25.

34. Repse S, Pepe S, Anderson J, McLean C, Rosenfeldt FL. Cardiac reanimation for donor heart transplantation after cardiocirculatory death. J Heart Lung Transplant. 2010;29:747-55.

35. White CW, Ali A, Hasanally D, Xiang B, Li Y, Mundt P, et al. A cardioprotective preservation strategy employing ex vivo heart perfusion facilitates successful transplant of donor hearts after cardiocirculatory death. J Heart Lung Transplant. 2013;32:734-43.

Key Words: heart transplantation, cardiac arrest, heart donor, heart recipient, outcome

Readers who found these articles interesting may also like to read the following papers found in recent and future issues of our sister publications, Seminars in Thoracic and Cardiovascular Surgery and Operative Techniques in Thoracic and Cardiovascular Surgery!

\section{Acquired: Transplantation and Mechanical Circulatory Support}

Original Submission: Rotary Blood Pumps as Long-Term Mechanical Circulatory Support: A Review of a 15-Year Berlin Experience. Roland Hetzer. Semin Thoracic Surg 2016; 28:12-23.

Editorial Commentary: Insights and Perspectives into Durable Mechanical Circulatory Support with Continuous Flow Technology from the Deutsches Herzzentrum Berlin. Francis D. Pagani. Semin Thoracic Surg 2016; 28:24-25.

Original Submission: Trends in U.S. Extracorporeal Membrane Oxygenation Use and Outcomes: 2002-2012. Fenton H. McCarthy. Semin Thoracic Surg 2015; 27:81-88.

Editorial Commentary: Is it Worth it to Increase the Use of Extracorporeal Membrane Oxygenation? Marco Morsolini. Semin Thoracic Surg 2015; 27:89-90.

Total Artificial Heart Replacement with 2 Centrifugal Blood Pumps. Carmelo Milano. Oper Tech Thorac Cardiovasc Surg 2015; 20:306-321.

Organ Care System for Heart Procurement and Strategies to Reduce Primary Graft Failure After Heart Transplant. Yoshifumi Naka. Oper Tech Thorac Cardiovasc Surg 2015; 20:322-334. 